MATEC Web of Conferences 41, 04001 (2016)

DOI: $10.1051 /$ matecconf/20164104001

(c) Owned by the authors, published by EDP Sciences, 2016

\title{
Development of layered anode structures supported over Apatite-type Solid Electrolytes
}

\author{
P.Pandis ${ }^{1}$, T.Kharlamova ${ }^{2}$, V. Sadykov ${ }^{3}$ and V.N. Stathopoulos ${ }^{1, a}$ \\ ${ }^{1}$ Laboratory of Chemistry \& Materials Technology, School of Technological Applications, TEISTE, 34400, Psachna, Greece \\ ${ }^{2}$ Tomsk State University, Tomsk 634050, Russia \\ ${ }^{3}$ Boreskov Institute of Catalysis, Novosibirsk State University, Novosibirsk 630090, Russia
}

\begin{abstract}
Apatite-type lanthanum silicates (ATLS) materials have attracted interest in recent literature as solid electrolytes for SOFCs. The fabrication of an ATLS based fuel cell with the state-of-art electrodes (NiO/YSZ as anode and LSCF or LSM as cathode) can show degradation after long operation hours due to Si diffusion mainly towards the anode. In this work, we report a "layer-by-layer anodic electrodes" fabrication by means of spin coating and physical spraying. The overall aim of this work is the successful fabrication of such a layered structure including suitable blocking layers towards the inhibition of $\mathrm{Si}$ interdiffusion from the apatite electrolyte to the anode. The results showed that the deposition of 3 layers of LFSO/GDC $(3 \mu \mathrm{m}), \mathrm{NiO} / \mathrm{GDC}(4 \mu \mathrm{m})$ and the final NiO/YSZ anode layer provided a stable half-cell, with no solid state reaction occurring among the electrodes and no Si diffusion observed towards the anode after thermal treatment at $800^{\circ} \mathrm{C}$ for $120 \mathrm{~h}$.
\end{abstract}

\section{Introduction}

Two major problems hinder the overall performance of a solid oxide fuel cells: the improper electrode layer deposition and the solid state phenomena and cation interdiffusion from sealants, pastes and even from electrolyte towards the electrodes leading to cell degradation.

Also, another issue hindering large-scale practical application of SOFCs based on the state-of-the-art YSZ electrolyte is its high operating temperature $\left(\sim 1000^{\circ} \mathrm{C}\right)$. Thus the past years alternative types of electrolytes have been investigated in order to overcome the aforementioned disadvantages [1-4]. Fe- and Al- doped apatite-type lanthanum silicates (ATLS) have attracted the interest due to their thermodynamic stability, robustness and their high ionic conductivity at intermediate temperatures [5-8]. Not many researchers have tried to fabricate and study ATLS electrolyte based fuel cells for an estimation of cell performance and degradation with state of the art electrodes [9-12].

In this study, a systematic work on the development of electrolyte supported anodic half-cell is reported. The anode is a composite structure based on GDC, NiO/GDC and $\mathrm{NiO} / \mathrm{YSZ}$ layers. Deposition is performed by means of spin coating and physical spraying techniques. More specifically, a GDC/ATLS layer is deposited directly over the ATLS electrolyte. A layer of NiO/GDC cermet is applied as an intermediate functional layer. Finally a $\mathrm{NiO} / \mathrm{YSZ}$ layer is applied as the final anode electrode. GDC/ATLS layer is applied over the electrolyte in order

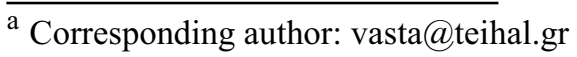

to block possible cation interdifussion from the electrolyte to the anode layer. A combination of the spin coating and physical spraying techniques is applied for the production of such layered half cells. A co-sintering technique was applied in order to aid the development of the layered structured electrode.

\section{Experimental}

The first major problem mentioned is overcomed in this work by deploying techniques such as spin coating and physical spraying. Due to the elemental composition of the electrolyte (La9.83 $\mathrm{Si}_{4.5} \mathrm{Fe}_{1.5} \mathrm{O}_{26 \pm \delta} \quad-\quad$ LFSO) the interdiffusion of $\mathrm{Si}$ from the electrolyte to the anode layer is also examined. The overall concept is based on the idea of the subsequent deposition of anodic layers onto dense apatite pellet by means of spin coating and physical spraying in order to provide a coherent and solid structure of anodic-based layered structured on dense apatite-type electrolyte in order to overcome the aforementioned issues. The experimental methodology of layered anode structures is depicted at Figure 1 which shows the layerby-layer fabrication of apatite-type supported anodic halfcell.

Subsequent coating and firing methodology is applied throughout the whole anodic layer electrode deposition. The first layer is considered as the blocking $\mathrm{Si}$ layer (BL) whilst the use of the functional $\mathrm{NiO} / \mathrm{GDC}$ porous layer (FL) is demanded in order to eliminate the mismatch of thermal expansion coefficients (TEC) of LFSO/GDC layer (BL) and (AL). 


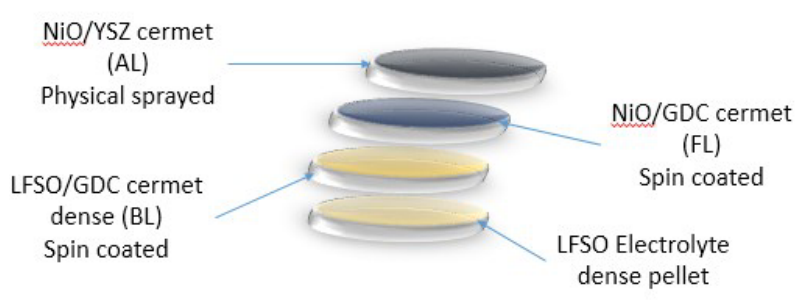

Figure 1. Layer-by-layer fabrication of anode starting from top to bottom.

\subsection{Production and characterization of dense apatite-type electrolyte pellets}

LFSO powder was prepared through a combined technique of mechanochemical activation (MA) and solid state synthesis (SS). More specifically, $\mathrm{La}_{2} \mathrm{O}_{3}$, was preannealed at $600^{\circ} \mathrm{C}$ for $2 \mathrm{~h}$ in order to eliminate humidity and impurities. Stoichiometric quantities of the preannealed $\mathrm{La}_{2} \mathrm{O}_{3}, \mathrm{Fe}(\mathrm{HCOO})_{3}$ and $\mathrm{SiO}_{2}$ were ball-milled in ethanol for $24 \mathrm{~h}$ and the mix was then treated at $800^{\circ} \mathrm{C}$ for 4h. The product was ball-milled, calcined at $1000{ }^{\circ} \mathrm{C}$ for $2 \mathrm{~h}$ and was further induced to mechanical activation in a high-power (1200 rpm) planetary ball mill AGO-2 for $20 \mathrm{~min}$ (steel drums and balls, sample-to-ball mass ratio $1 / 20$ ) in order to provide a powder with a particle size of $5+35 \mu \mathrm{m}$ for pelletizing. The powder was uniaxial pressed at $25 \mathrm{~mm}$ diameter pellets (disks) and sintered in air at $\mathrm{t} 1500{ }^{\circ} \mathrm{C}$ for $2 \mathrm{~h}$ (heating and cooling rates of $2 \mathrm{~K} \mathrm{~min}{ }^{-1}$ ) to form dense pellets of $20 \mathrm{~mm}$ diameter and $1 \mathrm{~mm}$ thickness of the electrolyte. Relative density was measured with Archimedes method and crystal phase formation was followed by powder XRD diffraction on a Siemens D5000 diffractometer using $\mathrm{CuK} \alpha$ radiation, $\lambda=$ $1.5406 \AA, 2 \theta$ range from $20-75^{\circ}$ with scan step of $0.01^{\circ}$ \% $\min$

\subsection{Materials and slurries preparation for spin coating and physical spraying}

The materials used for the preparation of the slurries were all provided by Fuel Cell Materials (GDC-SKU: 114101, NiO/GDC-SKU: 131101, NiO/YSZ-SKU: 132301). The above powders $(\mathrm{P})$ or combination of them with LAFSO were mixed with two dispersants (D) (Darvan C \& Dolapix) in various ratios $\mathrm{P} / \mathrm{D}$ for each technique in order to provide a suitable slurry $(\mathrm{S})$ for the proper layer deposition. Table 1 depicts all the information for slurries preparation.

All the powders were thoroughly mixed with the dispersant toa stable slurry. Slurries were degassed under vacuum. The final slurries were studied for their rheological properties.

\subsection{Parameters of spin coating and physical spraying equipment}

A spin coater was used with the ability of housing pellets of various sizes $(10 \mathrm{~mm}-35 \mathrm{~mm})$ and a variable rotation speeds from 300-5850rpm.
For the physical spraying atomisation was achieved by a Sprayer Model \#TC108 using a standard nozzle of $0.8 \mathrm{~mm}$ diameter and air pressure of $4 \mathrm{bar}$.

The parameters of layering deposition are depicted in Table 2 for the spin coating of (BL) and (FL). Table 3 shows the experimental procedure and parameters of physical spraying of (AL

Table 1. Slurries preparation of layering deposition

\begin{tabular}{|c|c|c|c|}
\hline $\begin{array}{c}\text { Slurry } \\
\#\end{array}$ & $\begin{array}{l}\text { Powder } \\
\text { (P) }\end{array}$ & $\begin{array}{c}\text { Dispersants } \\
\text { (D) }\end{array}$ & $\begin{array}{c}\text { P/D ratio } \\
(\mathbf{w} / \mathbf{v} \%)\end{array}$ \\
\hline 1 & $\begin{array}{c}\text { LFSO } \\
(80 \mathrm{wt} \%) \\
+\mathrm{GDC} \\
(20 \mathrm{wt} \%)\end{array}$ & \multirow[t]{3}{*}{$\begin{array}{c}\text { Darvan C, } \\
\text { Dolapix }\end{array}$} & 50 and 75 \\
\hline 2 & $\begin{array}{c}\text { LFSO } \\
(75 w t \%) \\
+ \text { GDC } \\
(25 w t \%)\end{array}$ & & 50 and 75 \\
\hline 3 & $\mathrm{NiO} / \mathrm{GDC}$ & & 50 and 75 \\
\hline 4 & $\mathrm{NiO} / \mathrm{YSZ}$ & Dolapix & 5 and 10 \\
\hline
\end{tabular}

Table 2. Spin coating parameters for (BL) and (FL)

\begin{tabular}{|c|c|c|c|c|c|c|}
\hline layer & $\begin{array}{c}\text { Slurry } \\
\#\end{array}$ & $\begin{array}{c}\text { P/D } \\
\text { ratio } \\
(\mathbf{w} / \mathbf{v})\end{array}$ & $\begin{array}{c}\text { Vol. } \\
(\mathbf{m l})\end{array}$ & $\begin{array}{c}\text { Speed } \\
(\mathbf{r p m})\end{array}$ & $\begin{array}{c}\text { Time } \\
(\mathbf{s})\end{array}$ & Passes \\
\hline (BL) & 1 & 75 & 2 & 2200 & 20 & 4 \\
\hline (BL) & 2 & 50 & 2 & 2000 & 30 & 5 \\
\hline (BL) & 2 & 75 & 2 & 2000 & 30 & 5 \\
\hline (FL) & 3 & 75 & 5 & 1800 & 30 & 3 \\
\hline (FL) & 3 & 50 & 1 & 1600 & 30 & 3 \\
\hline
\end{tabular}

Table 3. Physical Spraying parameters

\begin{tabular}{|c|c|c|c|c|c|}
\hline Layer & $\begin{array}{c}\text { Slurry } \\
\#\end{array}$ & $\begin{array}{c}\text { P/D } \\
\text { ratio } \\
(\mathbf{w} / \mathbf{v} \%)\end{array}$ & $\begin{array}{c}\text { Distance } \\
\text { from } \\
\text { surface } \\
\text { (cm) }\end{array}$ & $\begin{array}{c}\text { Time } \\
\text { (s) }\end{array}$ & Passes \\
\hline (AL) & $\# 4$ & 5 & 20 & \multirow{2}{*}{6} & \\
\cline { 3 - 4 } & & 5 & 15 & & 5 \\
\cline { 3 - 4 } & & 10 & 15 & & 4 \\
\hline
\end{tabular}

After the deposition of each layer the substrates were dried at $90^{\circ} \mathrm{C}$. This step is necessary for the removal of the slurry volatiles in order to provide the optimum compaction of green layers towards final formation of dense or porous layers. After the last spraying pass of (BL) the specimen was treated at $1500^{\circ} \mathrm{C}$ for $1 \mathrm{~h}$ in order to densify the deposited blocking layer. For the (FL) the temperature of final treatment was $900^{\circ} \mathrm{C}$ for $2 \mathrm{~h}$ and finally after the deposition of (AL) the whole half-cell was calcined at $850^{\circ} \mathrm{C}$ for $2 \mathrm{~h}$.

\subsection{Treatment \& study of half-cell}

After the preparation and the deposition of all the layers $\mathrm{LFSO} /(\mathrm{BL}) /(\mathrm{FL}) /(\mathrm{AL})$ all produced samples were posttreated at $800^{\circ} \mathrm{C}$ for $120 \mathrm{~h}$ in order to enhance Si diffusion to the $(\mathrm{AL})$ or possible solid state reactions between the electrodes. Scanning Electron Microscopy (SEM) and 
EDX analysis were performed on the cross section of the final pellets using a (JEOL6380LV) system in order to investigate microstructure as well as chemical and structural stability.

\section{Results and discussion}

\subsection{XRD of dense electrolyte}

The XRD results of the produced electrolytes are shown in Figure 2. LFSO exhibited single phased crystallographic structure at the hexagonal apatite structure in space group P36/m (176) (PDF\#00-0490443). The characteristic two major peaks of apatite structure at $2 \theta=30.76^{\circ}$ and $2 \theta=30.95^{\circ}$ indicated a small shift of $+0.02^{\circ}$ at LFSO indicating the doping effect of $\mathrm{Fe}$ into $\mathrm{Si}$ site of a stoichiometric apatite $\left(\mathrm{La}_{10} \mathrm{Si}_{6} \mathrm{O}_{26}\right)$ structure as reported in our former works [5-8]. From Archimedes method the dense pellets exhibited a relative density of $96 \%$, thus enabling LFSO as a suitable substrate of deploying layer deposition techniques.

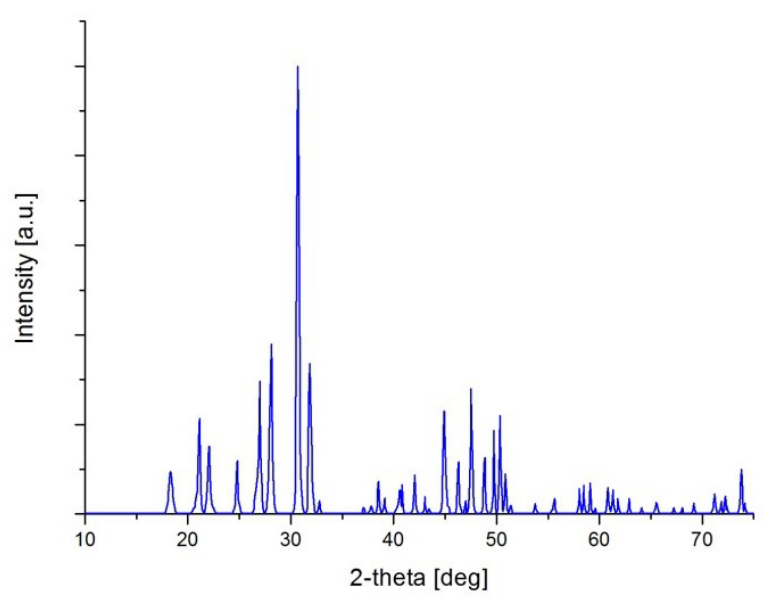

Figure 2. XRD pattern of the produced LFSO pellet

\subsection{Rheological results of produced slurries}

The prepared slurries (Table 1) were subject to rheological measurements. All slurries exhibited a pseudo elastic behaviour with a maximum viscosity for the slurry\#3. Such viscosity relates to the delivery of a porous structure by spin coating. The $\mathrm{P} / \mathrm{D}$ ratio of the first 2 slurries did not affect at all the rheological properties of the slurries $1 \& 2$ which is expected, due to the fact the viscosity seemed to be related to the particle size of the powders. Different particle sized powders led to different viscosities.

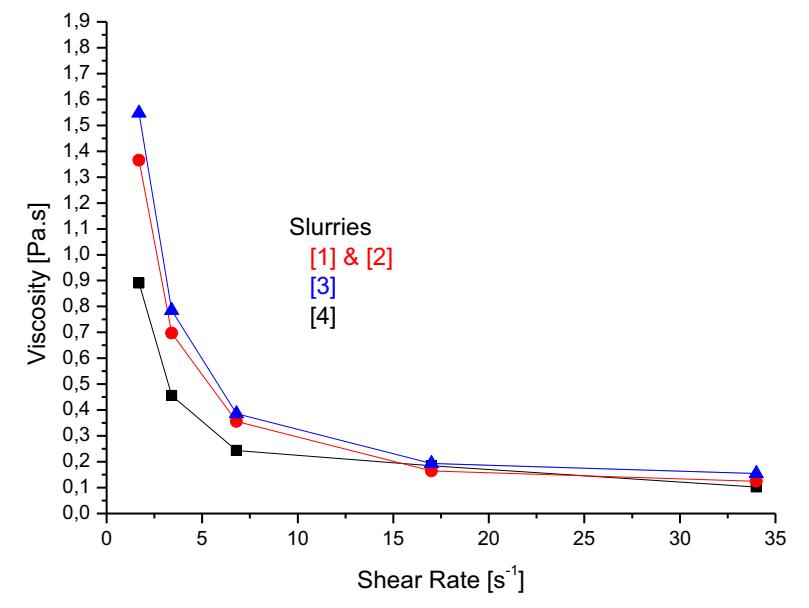

Figure 3. Rheological behaviour of produced slurries

\subsection{SEM Analysis}

The SEM analysis of LFSO pellet verified the dense structure of LFSO pellet as long as the porous structure of (AL). The results are shown in Figure 4.

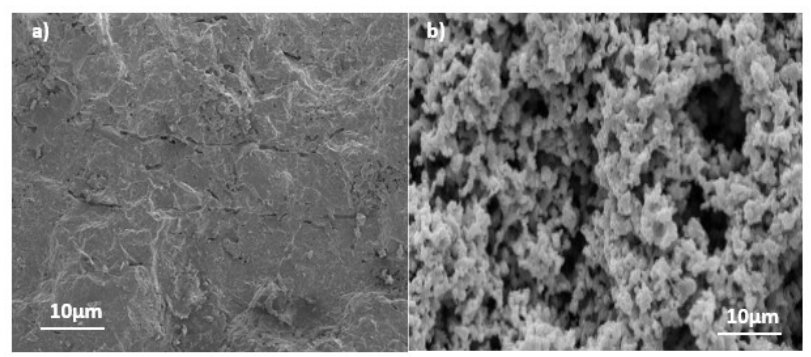

Figure 4. Top view of a) LFSO and b) $\mathrm{NiO} / \mathrm{YSZ}$
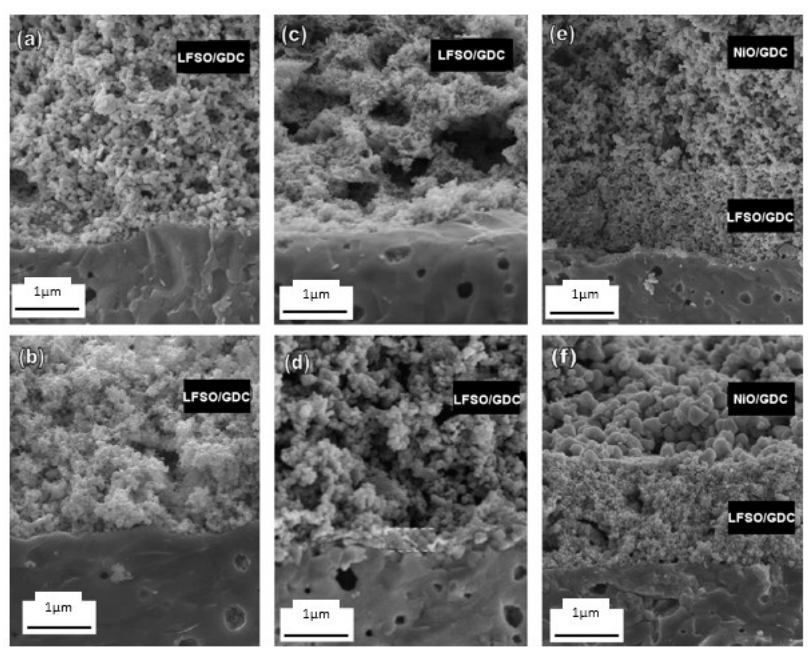

Figure 5. SEM images of layered anode structures on dense LAFSO electrolyte (bottom)

In Figure 5 SEM images of for the (BL) and (FL) deposition are depicted. The top row shows the results using Dolapix (5a,5c and 5e) as the dispersant for the spin coating technique. The bottom row presents the 
results using Darvan $C$ as the dispersant (5b, 5d and 5f). The specimens prepared using Darvan $\mathrm{C}$ provided the required dense structure of $(\mathrm{BL})$ as well as the porous structure of (FL) in a more homogenous deposition than using Dolapix.

The structure shown in Figure 5e was achieved using slurry \#1 at $220 \mathrm{rpm}$ with $\mathrm{P} / \mathrm{D}$ ratio of $75 \% \mathrm{w} / \mathrm{v}$ while structure shown in figure $5 \mathrm{f}$ prepared by using slurry\#3 at $1800 \mathrm{rpm}$ with same P/D ratio (see Table 2). Figure 5a and $5 \mathrm{~b}$ correspond to the structures prepared by using slurry\#2 for $(\mathrm{BL})$ with $\mathrm{P} / \mathrm{D}=75 \% \mathrm{w} / \mathrm{v}$. In Figures $5 \mathrm{c}$ and $5 \mathrm{~d}$ are shown structures prepared using slurry\#2 with $\mathrm{P} / \mathrm{D}$ $=50 \% \mathrm{w} / \mathrm{v}$. Optimum deposition of (BL) was achieved by using slurry\#3 at $1800 \mathrm{rpm}$ with $\mathrm{P} / \mathrm{D}=75 \% \mathrm{w} / \mathrm{v}$ (Table 2 in bold).

In Figure 6 a half cell structure is shown after applying optimum deposition parameters for both (BL) and (FL) (Table 2 in bold). Finally, the deposited thickness of each layer was $3 \mu \mathrm{m}$ of dense (BL) and $4 \mu \mathrm{m}$ of a porous (FL).

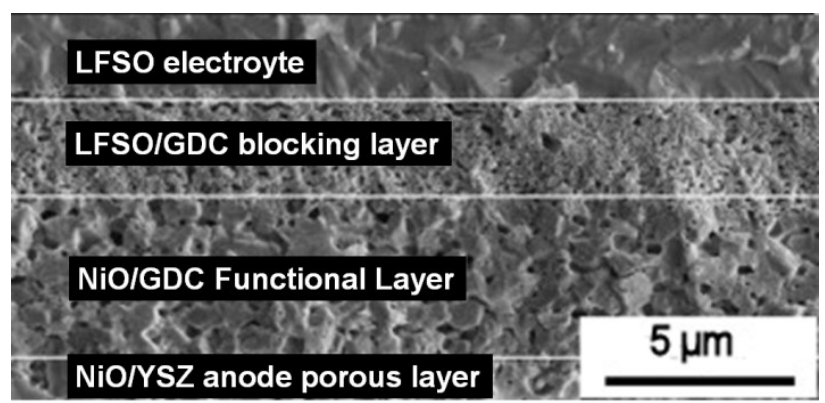

Figure 6. Cross-section SEM image depicting all the layers deposited

Results of EDX qualitative elemental analysis on the half cell structure shown in figure 6 are summarized in Table 4. No Si diffusion is observed either towards (FL) or (AL).

Table 4. EDX qualitative analysis on half-cell

\begin{tabular}{|l|l|l|l|l|l|l|l|l|}
\hline & $\mathrm{La}$ & $\mathrm{Si}$ & $\mathrm{Fe}$ & $\mathrm{Ni}$ & $\mathrm{Gd}$ & $\mathrm{Ce}$ & $\mathrm{Zr}$ & $\mathrm{Y}$ \\
\hline$(\mathrm{BL})$ & $\sqrt{ }$ & $\sqrt{ }$ & $\sqrt{ }$ & $\mathrm{X}$ & $\sqrt{ }$ & $\sqrt{ }$ & $\mathrm{X}$ & $\mathrm{X}$ \\
\hline (FL) & $\mathrm{X}$ & $\mathrm{X}$ & $\mathrm{X}$ & $\sqrt{ }$ & $\sqrt{ }$ & $\sqrt{ }$ & $\mathrm{X}$ & $\mathrm{X}$ \\
\hline$(\mathrm{AL})$ & $\mathrm{X}$ & $\mathrm{X}$ & $\mathrm{X}$ & $\sqrt{ }$ & $\sqrt{ }$ & $\sqrt{ }$ & $\sqrt{ }$ & $\sqrt{ }$ \\
\hline
\end{tabular}

\section{Conclusions}

Dense pellets of LFSO were successfully prepared via a combination technique of MA and SS synthesis. The depositions of all the 3 subsequent layers provided a solid structure of a half anodic cell that exhibits significant tolerance on Si diffusion from the electrolyte to the anode after $120 \mathrm{~h}$ at $800^{\circ} \mathrm{C}$. By spin coating technique a $3 \mu \mathrm{m}$ of dense LFSO/GDC Blocking Layer and a $4 \mu \mathrm{m}$ of porous NiO/GDC Functional Layer can be deposit after optimisation. The deposition of NiO/YSZ Anode Layer is achieved through physical spraying and its deposition was mainly performed in order to investigate Si diffusion from the electrolyte. Spin coating method can provide better layered structures using Darvan $\mathrm{C}$ as dispersant while Dolapix is delivering better layers by the physical spraying technique.

\section{Acknowledgements}

Financial support by the program Archimedes III - phase II - APACELL "Synthesis, Characterization and Study of Solid Electrolytes of the Apatite Structure for Fuel Cells Applications“, implemented within the framework of Education and Lifelong Learning Operational Programme, co-financed by the Hellenic Ministry of Education, Lifelong Learning and Religious Affairs is gratefully acknowledged.

\section{References}

1. Z.G. Yang, K.S.Weil, D.M. Paxton, J.W. Stevenson, J. Electrochem. Soc. 150, A1188 (2003)

2. T.A. Morris, E.A. Barrringer, S.C. Kung, R.W. McKain, MRS Bull, 30, 59 (2005)

3. W.Z. Zhu, S.C. Deevi, Mater. Sci. Eng. 227, A 348 (2003)

4. Z.G. Yang, Inter. Mater. Rev. 53, 39 (2008)

5. T. Kharlamova, S. Pavlova, V. A. Sadykov, Y. Bespalko, T. Krieger, O. Lapina, D.Khabibulin, V. Muzykantov, M. Chaikina, N. Uvarov, Y. Pavlukhin, V. Kriventsov, S. Petrov, C. Argirusis and V. Kaichev, ECS Trans. 25, 1791 (2009)

6. H. Gasparyan, C. Argirusis, C. Szepanski, G. Sourkouni, V. Stathopoulos, T.Kharlamova, V. A. Sadykov and S.Bebelis, ECS Trans. 25, 2681 (2009)

7. H. Gasparyan, S. Neophytides, D. Niakolas, V. Stathopoulos, T. Kharlamova, V.Sadykov, O. Van der Biest, E. Jothinathan, E. Louradour, J.-P. Joulin, S. Bebelis, Solid State Ionics 192, 158 (2011)

8. V. Sadykov, E. Sadovskaya, A. Bobin, T. Kharlamova, N. Uvarov, A. Ulikhin, C. Argirusis, G. Sourkouni and V. Stathopoulos, Solid State Ionics 271, 69 (2015)

9. P. Jasinski, S. Molin, M. Gazda, V. Petrovsky, H.U. Anderson, J. Power Sources 194, 10 (2009)

10. Y. Ma, N. Fenineche, O. Elkedim, Comput. Mater. Sci. 109, 25 (2015)

11. D. Marrero-López, M.C. Martín-Sedeño, J. PeñaMartínez, J.C. Ruiz-Morales, P. Núñez, M.A.G. Aranda, J.R. Ramos-Barrado, J. Power Sources 195, 2496 (2010)

12. Y. Nojiri, S. Tanase, M. Iwasa, H. Yoshioka, Y. Matsumura, T. Sakai, J. Power Sources 195, 4059 (2010) 